\title{
PREPARATION AND CHARACTERIZATION OF THE EMAMECTIN BENZOATE/HYDROXYPROPYL-B- CYCLODEXTRIN INCLUSION COMPLEX
}

\author{
PABLO TORRES ${ }^{I}$, FRANCISCO VILLA, JAVIER GONZÁLEZ ${ }^{2}$, JOSÉ TRONCOSO ${ }^{2}$ AND CARLOS VON \\ PLESSING $^{{ }^{*}}$
}

\author{
${ }^{I}$ Department of Pharmacy, Faculty of Pharmacy, Casilla 237 Correo-3,Universidad of Concepción, Chile \\ ${ }^{2}$ Ewos Innovation, Benavente 50, Torre Campanario, Puerto Montt, Chile
}

(Received: August 2, 2011 - Accepted: September 15, 2011)

\begin{abstract}
The objective of this study was to prepare an inclusion complex of the insecticide emamectin benzoate (EB) with hydroxypropyl- $\beta$-cyclodextrin (HP- $\beta$-CD) by co-evaporation and spray drying methods. The complexation of both compounds was evaluated on the aqueous and solid state using phase solubility diagrams, differential scanning calorimetry (DSC), X-Ray diffraction (XRD), Fourier transform infrared spectroscopy (FT-IR) and scanning electron microscopy (SEM). The aqueous solubility of the inclusion complexes at $\mathrm{pH} 8 \mathrm{had}$ a 2 -fold increase respect to the drug alone and dissolution profiles showed a rise in the dissolution rate. These results suggest that the use of HP- $\beta-C D$ could be an interesting alternative to enhance the bioavailability of EB in salmons.
\end{abstract}

Key Words: Emamectin benzoate, cyclodextrin, inclusion complex, salmon.

\section{1.- INTRODUCTION}

Emamectin benzoate, (4'"R)-4"-deoxy-4"-(methylamino)avermectin b1 benzoate, is one of the most widely used compounds in the salmon industry. Chemically, is a semisynthetic derivative of avermectins (Figure 1), which shows insecticide properties against the sea lice (Lepeophteirus salmonis), an ectoparasite that infests farmed salmons ${ }^{1-3}$. Unfortunately, it has been demonstrated that the efficacy of anti-infective treatments in salmons and trouts is low because is very difficult to control the dosage in medicated foods, which results in high intra-inter variability in plasma concentrations of the agents used ${ }^{4-6}$ Of the approaches considered for improvement of the accuracy in the administration of EB, Glover et al. demonstrated that the intraperitoneal injection of the drug in farmed salmons resulted in higher and more predictable concentrations, but there are constraints that have relation with the manipulation of individual specimens ${ }^{7}$. From a point of view of the drug, one of the factors that influence the bioavailability of active compounds in living systems are their physicochemical properties like the solubility, which is often the limiting step in the absorption process. EB is a compound that has an erratic bioavailability and poor water solubility, which depends on the $\mathrm{pH}$ of the aqueous medium. At $\mathrm{pH}$ higher than 7, the solubility is drastically reduced and this is a relevant issue, because the intestinal $\mathrm{pH}$ of some fish can reach values of $7-9^{8}$. Actually, the salmon industry is concerned about the need for optimize the therapeutic regimes, and one way to achieve predictable drug concentrations in plasma and tissues (taking into account the low and $\mathrm{pH}$ dependent solubility of EB) after an oral dose of a drug is improving its aqueous solubility with the use of cyclodextrins ${ }^{9-12}$. Of all the cyclodextrins used, hydroxypropyl- $\beta$-cyclodextrin (HP- $\beta-C D$ ) has been the most studied, because of its toxicological profile and better aqueous solubility ${ }^{13-15}$.

Since there is no evidence of previous research, the aim of this work is to study the possibility of form an inclusion complex of EB and HP- $\beta$ $\mathrm{CD}$, characterizing the final product in its physicochemical and dissolution properties.

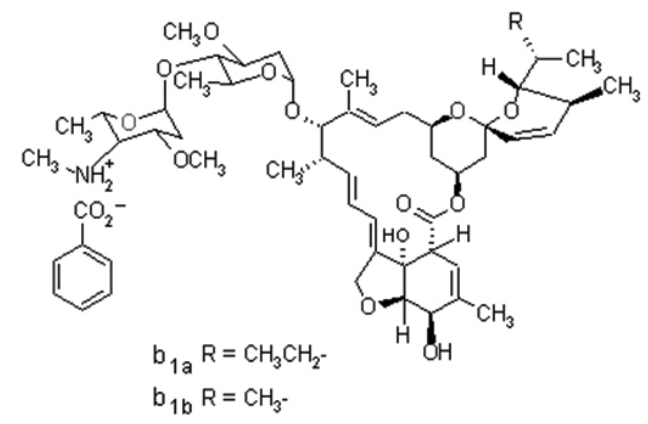

Figure 1: Chemical structure of emamectin benzoate.

\section{2.- MATERIALS AND METHODS}

\section{1.- Materials}

EB $\left(b_{1 a}=91.53 \%\right)$ was purchased from Hebei Lianli Chemical Tech Ltd., China, EB PESTANAL ${ }^{\circledR}$ analytical standard $\left(\mathrm{b}_{1 \mathrm{a}}=93.83 \%, \mathrm{~b}_{1 \mathrm{~b}}=5.55 \%\right)$ and HP- $\beta$-CD (MW: 1380 ; degree of substitution: 0.6 ; water percentage: $8 \%$ ) were purchased from Sigma-Aldrich, USA. All other reagents were of analytical grade and deionized water was used for all the experiments.

\section{2.- Phase solubility diagrams}

Phase solubility diagrams were performed in deionized water $(\mathrm{pH}=5.6)$ and Phosphate buffer $0,1 \mathrm{M}$ at $\mathrm{pH} 8$, according to the method reported by Higuchi and Connors ${ }^{16}$. An excess of EB $(50 \mathrm{mg})$ was added to $4 \mathrm{~mL}$ of each aqueous medium with increasing concentrations of HP- $\beta-C D(0-0.0092 \mathrm{M})$. The suspensions were homogenized and shaken for 3 days at a temperature of $20^{\circ} \mathrm{C}$. At the end of time, the suspensions were filtered through a $0.22 \mu \mathrm{m}$ filter (Millipore, USA) and the concentration of $\mathrm{b} 1_{\mathrm{a}} \mathrm{EB}$ was determined by HPLC. Each experiment was performed in triplicate, and the stability constants $\mathrm{K}_{\mathrm{s}}$ were calculated according to the Higuchi and Connors equation (1965).

$$
K_{s}=\frac{a}{S \bullet(1-a)}
$$

Where $a$ is the slope and $\mathrm{S}$ is the solubility of $\mathrm{b}{ }_{\mathrm{a}} \mathrm{EB}$ at $20^{\circ} \mathrm{C}$ in absence of cyclodextrin, at each $\mathrm{pH}$.

\section{3.- HPLC determination of $E B$}

EB was determined by HPLC using an adapted method from Farer et a ${ }^{17}$. Briefly, the HPLC system was a LaChrom Elite (Hitachi, Japan), equipped with a Diode array detector and autosampler. The column used was a Symmetry C8 $250 \times 4.6 \mathrm{~mm} 5 \mu \mathrm{m}$ particle size (Waters, Ireland). The wavelength used for detection of EB was fixed at $244 \mathrm{~nm}$, the injection volume was $20 \mu \mathrm{L}$ and the retention time of the $\mathrm{b}_{1 \mathrm{a}}$ compound was 9 minutes.

The method was validated through the concentration range of $0.9-36 \mu \mathrm{g} /$ $\mathrm{mL}$, injecting each dilution by triplicate.

\section{4.- Preparation of the inclusion complexes}

The inclusion complexes were prepared using a molar ratio of 1:1, by coevaporation and spray drying methods.

The co-evaporated complex was prepared by dissolving the weighted amount of HP- $\beta-C D$ in ethanol. Then, EB was added and the mixture was stirred for 48 hours at ambient temperature. Ethanol was evapored at $50^{\circ} \mathrm{C}$ by reduced pressure using a rotavapor (Heidolph, Germany) and the binary mixture was dried in an oven at $50^{\circ} \mathrm{C}$ for 48 hours.

The spray-dried product was prepared dissolving equimolar amounts of EB and HP- $\beta-C D$ as previously described in the co-evaporated complex. Ethanol was evaporated using a B-290 Mini Spray Dryer (Büchi, Switzerland) 
with the following conditions: Inlet temperature $110^{\circ} \mathrm{C}$, outlet temperature $60^{\circ} \mathrm{C}$, aspiration rate $75 \%$, and flow of $5 \mathrm{ml} / \mathrm{min}$. The final product was dried in an oven at $50^{\circ} \mathrm{C}$ for 48 hours.

\section{5.- Preparation of the physical mixture}

The physical mixture was prepared by gently mixing of EB and HP- $\beta-C D$, using a molar ratio of $1: 1$.

\section{6.- Morphological examination of the inclusion complexes}

Morphological properties of the inclusion complexes were examined using a JSM-6380 LV scanning electronic microscope (JEOL, Japan). Samples were mounted onto an aluminum stab, and then were sputter coated with gold for 60 seconds.

\section{7.- Differential scanning calorimetry (DSC)}

DSC analyses were carried on a DSC 822 system (Mettler Toledo, Germany). An amount of sample equivalent to $1 \mathrm{mg}$ of EB was weighted in an aluminum pan. The analysis conditions were adjusted in the range of $50-250$ ${ }^{\circ} \mathrm{C}$, with a scanning rate of $10^{\circ} \mathrm{C} / \mathrm{min}$, under a flow of $20 \mathrm{~mL} / \mathrm{min}$ of nitrogen.

\section{8.- Powder X-Ray Diffractometry}

$\mathrm{X}$-Ray patterns of raw materials, physical mixture and inclusion complexes were obtained from a X-Ray Diffractometer (Brüker, Switzerland), with Ni filtered $\mathrm{Cu}-\mathrm{K} \alpha$ line as the source of radiation, at a voltage of $40 \mathrm{kV}$, and a current of $20 \mathrm{~mA}$. All samples were measured over the range of $3-40^{\circ} 2 \theta$, with a scan step of 0.05 .

\section{9.- FT-IR Spectroscopy}

The infrared spectra of raw materials, physical mixture and inclusion complexes were obtained from a Nexus FT-IR spectrophotometer (Nicolet, USA). All the compounds were mixed in a mortar with Potassium Bromide, and the mix was pressed to form a tablet. The data was collected through the wavelength range between 4000 and $500 \mathrm{~cm}^{-1}$.

\subsection{0.-Maximum solubility of the complexes at $\mathrm{pH} 8$}

An excess of the inclusion complexes were added to $4 \mathrm{~mL}$ of $0,1 \mathrm{M} \mathrm{pH}$ 8 phosphate buffer. Then, the suspensions were shaken for 72 hours in a thermostatized bath at $20^{\circ} \mathrm{C}$, and the samples were filtered through a $0.22 \mu \mathrm{m}$ Millex membrane filter (Millipore, USA) for the HPLC analysis, diluting if necessary. Each experiment was performed in triplicate.

\subsection{1.- Dissolution testing}

Dissolution profiles of EB and its inclusion complexes were performed on a TDT-08L Dissolution Tester (Electrolab, India), using the paddle method at a stirring rate of $100 \mathrm{rpm}$ and a temperature of $18^{\circ} \mathrm{C}$. The dissolution media were $500 \mathrm{~mL}$ of deionized water and $0.1 \mathrm{M} \mathrm{pH} 8$ phosphate buffer; $1 \mathrm{~mL}$ of solution was taken at time intervals $(1,5,10,15,20,30,40,50,60 \mathrm{~min})$ and replaced by the same volume of aqueous medium. All samples were immediately filtered through a $0.45 \mu \mathrm{m}$ disk filter and the amount of b1 EB dissolved was determined using the previously described HPLC method.

\section{3.- RESULTS AND DISCUSSION}

\section{1.-Phase solubility diagrams}

Figure 2 shows the phase solubility diagrams performed in deionized water and $0,1 \mathrm{M} \mathrm{pH} 8$ phosphate buffer. There is a linear increase in the apparent solubility of b1 EB as a function of HP- $\beta-C D$ concentration, in both aqueous media, and the values of the slopes are lower than 1 . This observed behavior from the plots is characteristic of a $A_{L}$ system, suggesting the formation of a $1: 1$ inclusion complex.

The values of the slopes and apparent complexation constants are listed in table 1 . The slope of the phase solubility diagram performed in water is higher than the obtained with the phosphate buffer $\mathrm{pH} 8$, and this indicates that the solubilizing efficiency of HP- $\beta-C D$ is more evident in the first medium, but the value of $\mathrm{K}_{\mathrm{s}}$ is lower compared to the obtained at $\mathrm{pH}$ 8. It is demonstrated that $\mathrm{pH}$ plays an important role in establish the degree of interaction between the drug and the cyclodextrin, because the value of $\mathrm{K}$ at $\mathrm{pH} 8$, can be attributed to the unionization of $\mathrm{EB}$, which has pKa values of 4.2 (benzoic acid) and 5.2 (methyl-amino group of EB). This characteristic would promote a stronger interaction with the hydrophobic cavity of HP- $\beta-C D$.

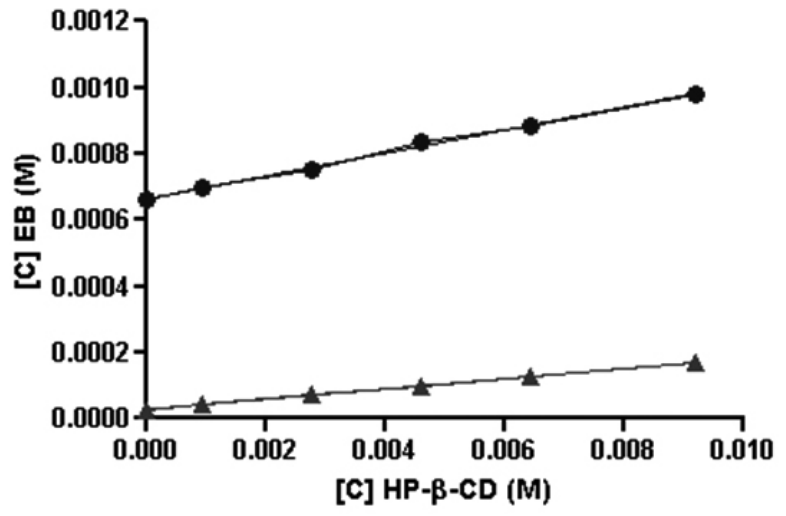

Figure 2 : Phase solubility diagrams of $b_{13}$ EB - HP- $\beta$-CD in water $\mathrm{pH} 5.6$ $(\boldsymbol{\bullet})$ and phosphate buffer $\mathrm{pH} 8.0(\boldsymbol{\Delta})$.

Table 1: Slopes and Complexation constants of EB - HP- $\beta-C D$ at $20^{\circ} \mathrm{C}$.

\begin{tabular}{|c|c|c|c|c|}
\hline Solvent & $\mathbf{S}_{\mathbf{0}}(\mathbf{M})$ & Slope & $\mathbf{K}_{\mathbf{s}}\left(\mathbf{M}^{-1}\right)$ & $\mathbf{r}^{\mathbf{2}}$ \\
\hline Water & $6,62 \times 10^{-4}$ & $0,0347 \pm 0.0011$ & 54,3 & 0,984 \\
\hline Buffer pH 8.0 & $2,73 \times 10^{-5}$ & $0,0153 \pm 0.0004$ & 569,1 & 0,991 \\
\hline
\end{tabular}

\section{2.- Morphological examination of the inclusion complexes}

The SEM micrographs of raw materials, physical mixture and inclusion complexes are shown in figure 3 .

From the raw materials, it can be noted that EB crystals do not have a homogeneous shape and size and HP- $\beta-C D$ particles have the characteristic amorphous spherical shape. The images of the physical mixture do not evidence an interaction between EB and HP- $\beta-\mathrm{CD}$, because the EB particles are clearly visible, surrounding the HP- $\beta-C D$ particles.

The co-evaporated complex does not share the morphological features of the raw materials. The particles have an irregular shape and size that suggest the formation of a new system, in which EB and HP- $\beta-C D$ interacts in a molecular level.

The spray dried complex, like the co-evaporated complex, have particles of different morphology, but in this case have an amorphous shrinked rounded shape with a narrow size range, proper of compounds dried by this methodology.

Finally, the SEM analysis gave visual evidence of the formation of an inclusion complex between EB and HP- $\beta-C D$, demonstrating that the inclusion complexes have morphological properties that are different from the raw materials and the physical mixture.

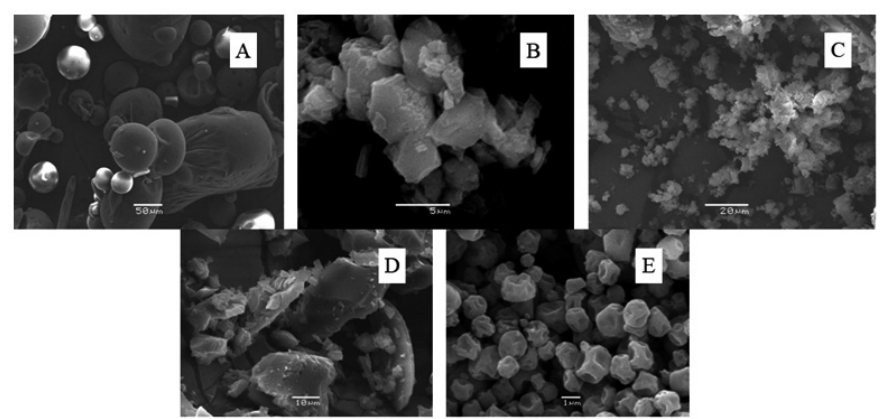

Figure 3 : SEM micrographs of HP- $\beta$-CD (A), EB (B), physical mixture (C), co-evaporated complex (D), spray dried complex (E).

\section{3.- Differential scanning calorimetry}

It has been demonstrated when a molecule forms an inclusion complex with a cyclodextrin, there is a shifting or a disappearance of the melting point peak $^{18,19}$. Figure 4 presents the DSC diagrams of EB, 1:1 physical mixture and inclusion complexes.

In the case of EB, there is an endothermic peak at $148^{\circ} \mathrm{C}$, corresponding to its melting point. The physical mixture thermogram still has the endothermic peak of the drug and the characteristic broad pattern of HP- $\beta$-CD between $35-$ $114^{\circ} \mathrm{C}$ that represents loss of water. However, in the co-evaporated and spray dried complexes thermograms, the peak of EB disappeared, suggesting the formation of an inclusion complex. 


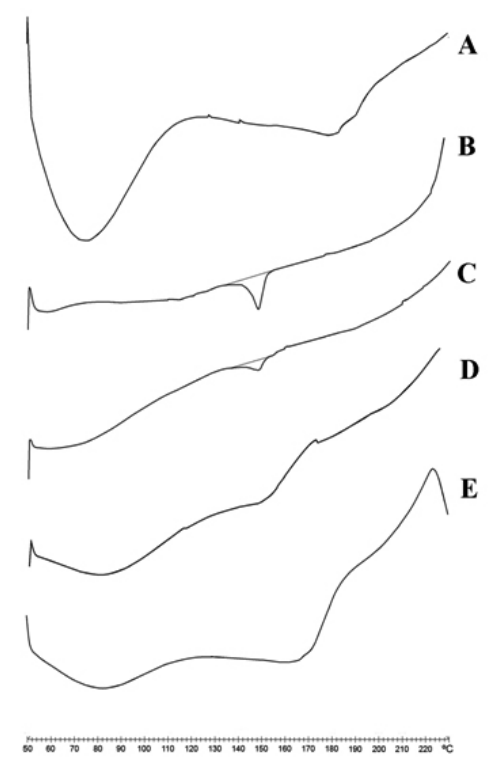

Figure 4: DSC thermograms of HP- $\beta$-CD (A), EB (B), physical mixture (C), co-evaporated complex (D), spray dried complex (E).

\section{4.- FT-IR Spectroscopy}

The FT-IR spectrums of EB, HP- $\beta$-CD, physical mixture and inclusion complexes are presented in figure 5. The spectra of HP- $\beta$-CD show the characteristic absorption band at $3600-3100 \mathrm{~cm}^{-1}$, corresponding to $\mathrm{O}-\mathrm{H}$ stretching vibrations. Other important peaks are at $2929 \mathrm{~cm}^{-1}(\mathrm{C}-\mathrm{H}$ stretching vibrations of $-\mathrm{CH},-\mathrm{CH}_{2}$ and $-\mathrm{CH}_{3}$ groups), $1645 \mathrm{~cm}^{-1}$ (O-H bending of HP$\beta-\mathrm{CD}$ and water) $1500-1350 \mathrm{~cm}^{-1}$ (C-H flexion), $1158 \mathrm{~cm}^{-1}$ (C-O-C flexion of glycosidic and eter bonds), 1090 and $1030 \mathrm{~cm}^{-1}$ (C-O and C-H stretching vibrations). In the case of $\mathrm{EB}$, there are absorption bands at $3412 \mathrm{~cm}^{-1}(\mathrm{~N}-\mathrm{H}$ and $\mathrm{O}-\mathrm{H}$ stretching vibrations), 3151 and $3050 \mathrm{~cm}$ (C-H stretching vibrations of an aromatic ring corresponding to the benzoate fraction or conjugated olefins), $1728 \mathrm{~cm}^{-1}(\mathrm{C}=\mathrm{O}$ stretching vibrations of an arylic ester), 1607, 1552 and $1456 \mathrm{~cm}^{-1}(\mathrm{C}=\mathrm{C}$ stretching vibrations of an aromatic ring or conjugated olefins), 1383 and $1330 \mathrm{~cm}^{-1}$ (C-H deformation in $\mathrm{CH}_{3}$ groups), 1164, 1113 and $1063 \mathrm{~cm}^{-1}$ (C-O stretching vibrations, $\mathrm{O}-\mathrm{H}$ and $\mathrm{C}-\mathrm{O}-\mathrm{C}$ flexion), $950 \mathrm{~cm}^{-1}$ (C-H flexion of trans $\mathrm{C}=\mathrm{C}$ bonding) and $900-600 \mathrm{~cm}^{-1}$ (C-H flexion outside the plane in an aromatic ring or $\mathrm{C}=\mathrm{C}$ cis bond). As seen in the figure, the IR spectra of the physical mixture, co-evaporated and spray dried complexes are different respect to the individual compounds. The peaks at 1645, 1033, 586 $\mathrm{cm}^{-1}$ corresponding to HP- $\beta-C D$ and $1728 \mathrm{~cm}^{-1}$, present in EB, were shifted in the inclusion complexes but not in the physical mixture, indicating there is a break down of the intramolecular hydrogen bonding and subsequently the formation of a new bonding between the HP- $\beta-C D$ and $\mathrm{EB}$ molecules in the solid state.

\section{5.- Powder X-Ray diffractometry}

Figure 6 shows the diffraction patterns of EB, physical mixture and inclusion complexes. As is expected, the XRD pattern of EB have peaks proper of a crystalline structure, while the HP- $\beta$-CD XRD pattern showed its amorphous character by the absence of crystalline peaks. In the case of the 1:1 physical mixture, the XRD pattern revealed the presence of some crystalline peaks, but is mainly a superposition of the patterns generated by the single compounds. However, the XRD patterns of the co-evaporated and spray dried complexes showed a complete absence of crystalline peaks, suggesting the formation of a new structure, in which EB probably is included in the hydrophobic cavity of HP- $\beta-C D$. It is described that a lack of crystallinity is indicative of the formation of an inclusion complex ${ }^{18-20}$.

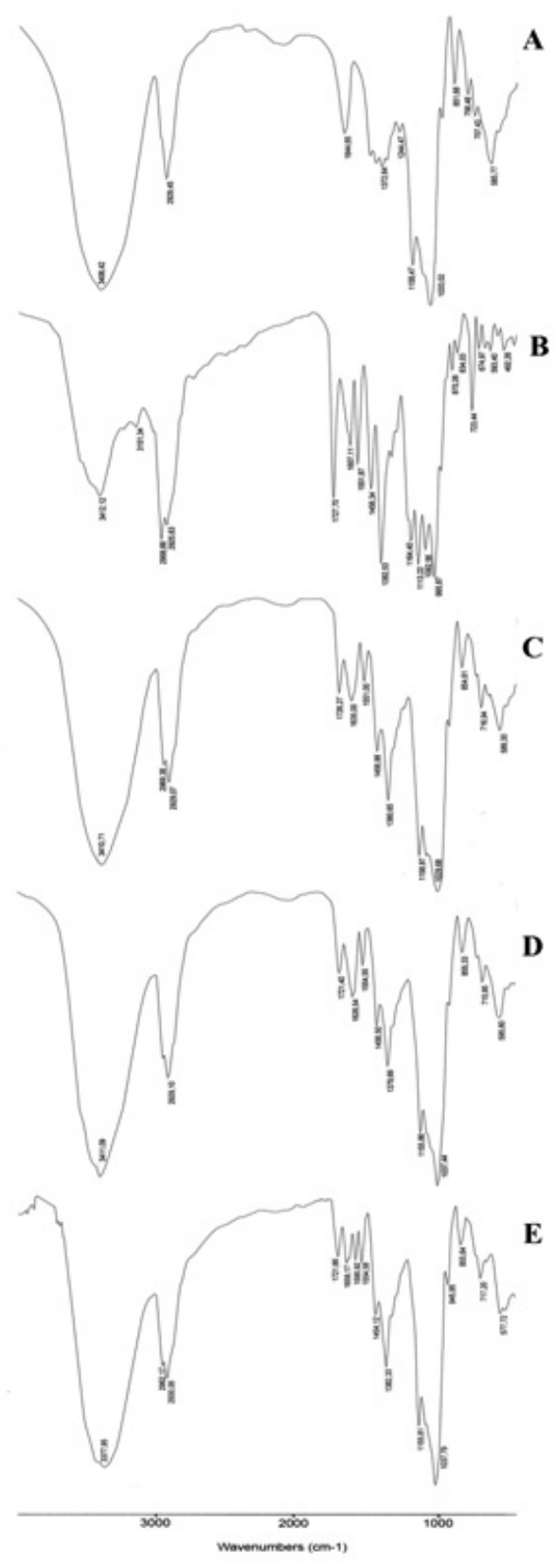

Figure 5 : FT-IR spectrograms of HP- $\beta$-CD (A), EB (B), physical mixture (C), co-evaporated complex (D), spray dried complex (E).

\section{6.- Maximum solubility of the inclusion complexes at pH 8}

EB is a basic drug whose solubility is reduced at higher $\mathrm{pH}$, and this characteristic can be a drawback when the drug is administered to salmons through medicated foods. At $\mathrm{pH} 8$, the solubility of EB was $20 \mu \mathrm{g} / \mathrm{mL}$, and the co-evaporated and spray-dried inclusion complexes solubility was 42.49 and $38.29 \mu \mathrm{g} / \mathrm{mL}$ respectively. In both complexes, there is an almost two-fold increase in EB solubility. 


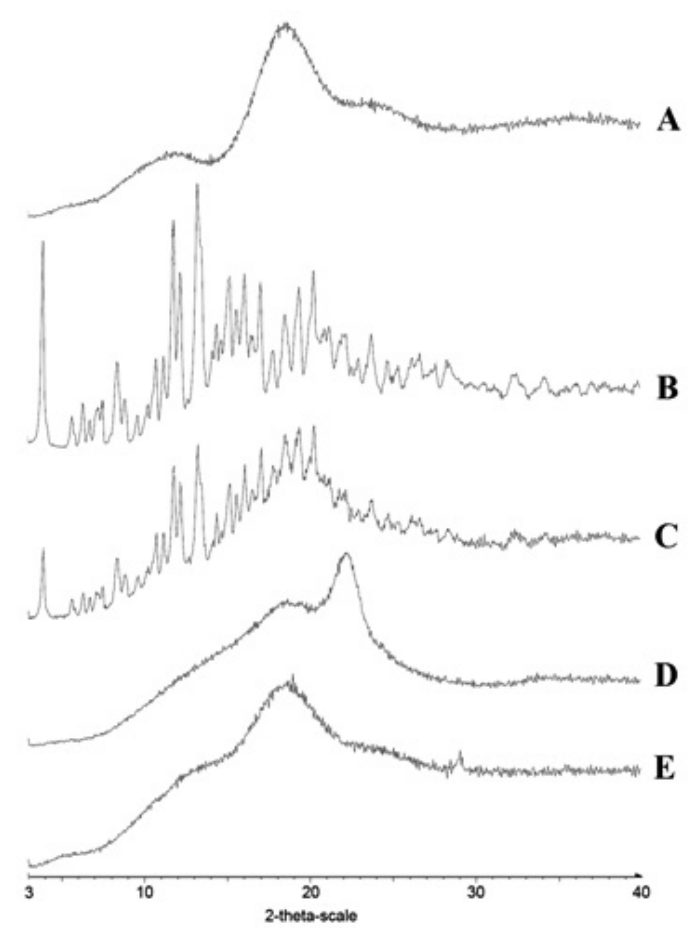

Figure 6: XRD patterns of HP- $\beta-C D(A), E B(B)$, physical mixture (C), co-evaporated complex (D), spray dried complex (E).

\section{7.- Dissolution testing}

Figure 7 presents the dissolution profiles of EB, and its inclusion complexes in water and phosphate buffer $\mathrm{pH} 8$ at $18^{\circ} \mathrm{C}$. The election of the temperature was based on the fact that this product is intended to be administered to salmons, not humans, so a working temperature of $37^{\circ} \mathrm{C}$ would not reflect the dissolution behavior of the drug and complexes at a temperature in which the salmon grows. It was not possible to reduce the temperature to less than $18^{\circ} \mathrm{C}$, because of ambient and instrumental constraints. In the profiles generated using water as the dissolution medium, the inclusion complexes showed a faster dissolution than the drug alone. However, at $\mathrm{pH} 8$, the effect of HP- $\beta-\mathrm{CD}$ on the dissolution of EB probably has more significance, because only a $15 \%$ of the complexed drug was dissolved 60 minutes compared to the $1 \%$ dissolved without the presence of HP- $\beta-C D$. As it was previously mentioned, the amount of drug dissolved can have a significant effect on the bioavailability and factors like the amorphous character and improved wettability of the complex may help to develop new and more efficient delivery systems for the administration of EB in fish species ${ }^{21}$.

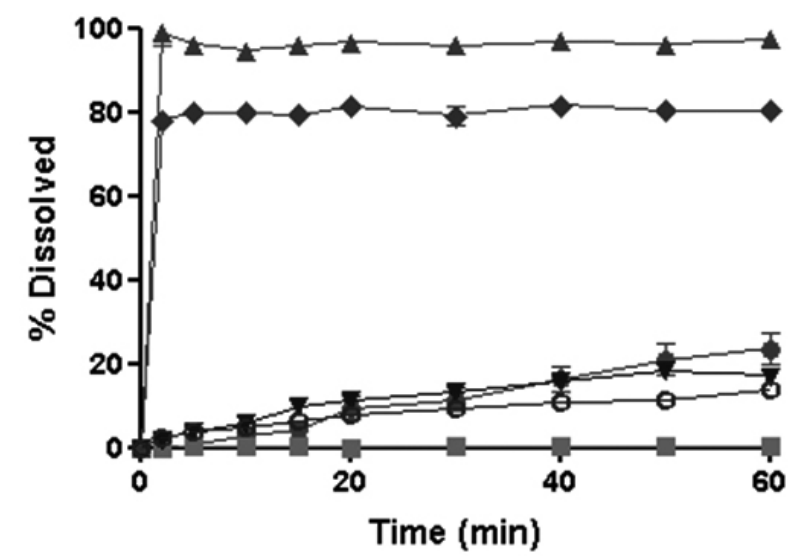

Figure 7 : Dissolution profiles of EB in water $(\bullet)$, EB in buffer pH $8(\mathbf{\bullet})$, co-evaporated complex in water $(\mathbf{\Delta})$, co-evaporated complex in buffer $\mathrm{pH} 8$ $(\boldsymbol{\nabla})$, spray dried complex in water $(\bullet)$, spray dried complex in buffer $\mathrm{pH} 8(\circ)$.

\section{4.- CONCLUSION}

From the results of this work, it was demonstrated that EB can form an inclusion complex with HP- $\beta$-CD. Further work will be conducted to evaluate if this physicochemical modification is capable to improve the bioavailability of the drug in animal models.

\section{ACKNOWLEDGEMENT}

This work was funded by INNOVA BIO-BIO Project 08-PC-S1-471, Chile. The authors also would like to acknowledge the support from EWOS Innovation and CIPA.

\section{REFERENCES}

1.- Bravo S., Sevatdal S., Horsberg T. Aquaculture, 282, 7 - 12 (2008)

2.- Stone J., Sutherland I.H., Sommerville C., Richards R.H., Varma K.J. J. Fish Dis., 22, 261 - 270 (1999)

3.- Treasurer J.W., Wallace C., Dear G. Bulletin of the European Association of Fish Pathologists, 22, 375-380 (2002)

4.- Berg A-G., Horsberg T. Aquaculture, 288, 22 - 26 (2009)

5.- Skilbrei O., Glover K., Samuelsen O., Lunestad B. Aquaculture, 285, 2 - 7 (2008)

6.- Roy W., GillanN., Crouch L., Parker R., Rodger H., Endris R. Aquaculture, 259,6 - 16 (2006)

7.- Glover K.A., Samuelsen O.B., Skilbrei O.T., Boxaspen K., Lunestad B.T. J. Fish Dis., 33, 183 - 186 (2009)

8.- Hesher B., (1990) Nutrition of pond fishes (1 ${ }^{\text {st }}$ edition). Cambridge University Press (Chapter 1).

9.- Brewster M., Loftsson T. Adv. Drug Delivery Rev., 59, 645 - 666 (2007)

10.- Liu L., Zhu S. J. Pharm. Biomed. Anal, 40, $122-127$ (2006)

11.- Zingone G., Rubessa F. Int. J. Pharm., 291, 3 - 10 (2005)

12.- Archontaki H., Vertzoni M., Athanassiou-Malaki M. J. Pharm. Biomed. Anal., 28, 761 - 769 (2002)

13.- Misiuk W., Zalewska M. Carbohydr. Polym., 77, 482 - 488 (2009)

14.- Zeng J., Rena Y., Zhoua C., Yua S, Chen W-H. Carbohydr Polym., 83, $1101-1105$ (2011)

15.- Gould S., Scott R. Food Chem. Tox., 43, 1451 - 1459 (2005)

16.- Higuchi, T., \& Connors, K.A. Adv. Anal. Chem. Inst., 4, 117-212 (1965)

17.- Farer L., Hayes J., Rosen J., Knight P. J. AOAC Int., 82(6), 1281-1287 (1999)

18.- Jun S.W., Kim M-S., Kim J-S., Park H.J., Lee S., Woo J-S., Hwangv S-J., Eur. J. Pharm. Sci., 66, 413-421 (2007)

19.- Eid E.E.M., Abdul A.B., Suliman F.E.O., Sukari M.A., Rasedee A., Fatah S.S., Carbohydr. Polym., 83, 1707-1714 (2011)

20.- Yap K.L., Liu X., Thenmozhiyal J.C., Ho P.C., Eur. J. Pharm. Sci., 25, 49-56 (2005)

21.- Rogel C., Mendoza N., Troncoso J., González J., von Plessing C., J. Chil. Chem. Soc., 56(1), 574-579 (2011) 